\title{
An algorithm for combining autonomous vehicles and controlled events in driving simulator experiments
}

Johan Olstam, Stéphane Espié, Selina Mårdh, Jonas Jansson and Jan Lundgren

\section{Linköping University Post Print}

N.B.: When citing this work, cite the original article.

Original Publication:

Johan Olstam, Stéphane Espié, Selina Mårdh, Jonas Jansson and Jan Lundgren, An algorithm for combining autonomous vehicles and controlled events in driving simulator experiments, 2011, Transportation Research Part C: Emerging Technologies, (19), 6, 1185-1201.

http://dx.doi.org/10.1016/j.trc.2011.02.003

Copyright: Elsevier http://www.elsevier.com/

Postprint available at: Linköping University Electronic Press

http://urn.kb.se/resolve?urn=urn:nbn:se:liu:diva-17451 


\title{
An algorithm for combining autonomous vehicles and controlled events in driving simulator experiments
}

\author{
Johan Olstam ${ }^{\mathrm{a}, \mathrm{b}, *}$, Stéphane Espiéc, Selina Mårdh ${ }^{\mathrm{a}}$, Jonas Jansson ${ }^{\mathrm{a}}$, Jan \\ Lundgren $^{\mathrm{b}}$ \\ ${ }^{a}$ Swedish National Road and Transport Research Institute (VTI), SE-581 95 Linköping, \\ Sweden \\ ${ }^{b}$ Linköping University, Department of Science and Technology (ITN), SE-601 74 \\ Norrköping, Sweden \\ ${ }^{c}$ INRETS (Institut National de REcherche sur les Transports et leur Sécurité), 58, Bd \\ Lefebvre F-75732 Paris, France
}

Keywords: Traffic simulation, Microscopic simulation, Driving simulators, Surrounding vehicles, Experimental design

*Corresponding author. Tel.:+46 132041 82; fax: +46 13141436

Email address: johan.olstam@vti.se (Johan Olstam) 


\begin{abstract}
Autonomous vehicles can be used to create realistic simulations of surrounding vehicles in driving simulators. However, the use of autonomous vehicles makes it difficult to ensure reproducibility between subjects. In this paper, an effort is made to solve the problem by combining autonomous vehicles and controlled events. A controlled event can be compared to a theatre play. The aim is to achieve the same initial play conditions for each subject, which can be problematic since the traffic situation around the subject will be dependent upon each subject's actions while driving in autonomous traffic. This paper presents an algorithm that achieves the transition from autonomous traffic to a predefined start condition for a play. The algorithm has been tested in the Swedish National Road and Transport Research Institute (VTI) driving simulator III with promising results. In most of the cases we examined the algorithm could reconstruct the specified start condition and conduct the transition from autonomous to controlled mode in a inconspicuous way. Some problems were observed regarding moving unwanted vehicles away from the closest area around the simulator vehicle, and this part of the algorithm has to be enhanced. The experiment also showed that the subjects drove faster in the presence of controlled everyday life traffic normally used in the VTI driving simulator than in autonomous traffic.
\end{abstract}




\section{Introduction}

Researchers conduct driver behavioral studies and experiments to gain knowledge of interactions between the driver, the vehicle, and the traffic system. These studies can be conducted in the real traffic system, on a test track, or in a driving simulator. The real world is of course the most realistic environment, but can be unpredictable with regards to weather and road and traffic conditions. The limited control possibilities often make it hard to design real world experiments with equivalent conditions for all subjects. Test tracks offer a safer environment and the possibility of giving the test drivers more equivalent conditions. However, they have drawbacks notably with regard to the variety and complexity of the driving context. Driving simulators, which are the focus of this paper, offer a less realistic environment compared to the real world, but one in which test conditions can be fully controlled and varied in a safe way.

A driving simulator is a tool which allows driving in a virtual environment. It is possible to reproduce many types of driving situations, from everyday life driving to specific situations, e.g. risky situations. Just as in real traffic situations, a main component of the driving context is the behavior of other road users. The main reason for choosing driving simulators for conducting driving behavior experiments is often to get increased controllability and reproducibility. In order to ensure high reproducibility, the behavior of the surrounding road users is often strictly controlled. The disadvantages are limited realism regarding the behavior of the surrounding vehicles and limitations in the complexity of the scenario situations, due to both the complexity of the scenario programming and the programming effort required. The complexity of programming can be decreased and realism increased by giving the surrounding road users increased autonomy. This leads to simulated situations with similar advantages and disadvantages to real world experiments, i. e. low reproducibility but realistic surroundings. Our hypothesis is that it is possible to gain in realism without losing too much in reproducibility by combining autonomous and controlled simulated road users.

Earlier work within the field of simulating surrounding vehicles in driving simulators has focused on the development of models for simulation of autonomous vehicles; see for example Al-Shihabi and Mourant (2002), Cremer et al. (1995), Espié (1995), Janson Olstam et al. (2008) or Wright et al. (2002). Ideas and frameworks, but no complete algorithms, for combining 
autonomous and controlled vehicles are provided by Alloyer et al. (1997), Wassink et al. (2005, 2006) and Janson Olstam and Espié (2007). Inspired by the work of Alloyer et al. (1997) and Wassink et al. (2005, 2006), Janson Olstam and Espié (2007) proposed an alternative design methodology for driving simulator experiments in which periods with autonomous simulated road users are combined with periods with only controlled simulated road users. The basic idea is to let the surrounding vehicles run in autonomous mode between the predetermined situations at which measurements are taken. When a subject approaches a position along the road where a situation is going to take place, the simulation of the surrounding vehicles should change from the autonomous to the controlled mode. The transition from autonomous to controlled mode has to be done in a way which is unnoticed by the subject. The idea is that the autonomous parts will ensure the necessary realism and the controlled part will ensure the required reproducibility. The controlled events are named Plays and the problem of changing from the autonomous to the controlled mode is referred to as the Play Preparation Problem. Possible approaches for solving the play preparation problem are discussed and outlined in Janson Olstam and Espié (2007), but no complete algorithms are presented or evaluated. The aim of this paper is to propose and evaluate an algorithm for solving the play preparation problem.

The paper is organized as follows. Section 2 gives an introduction to the play preparation problem and its sub-problems. The developed algorithm is then presented in Section 3. An evaluation of the algorithm including results from a driving simulator experiment is presented in Section 4. Section 5 ends the paper with conclusions and outlines for future research.

\section{The play preparation problem}

Janson Olstam and Espié (2007) define a driving simulator scenario as a constellation of the three components everyday life driving, preparations for plays, and plays (see Figure 1 for an example). Everyday life driving refers to the "normal" driving context on the present road type, i. e. the traffic conditions on the present road type when there are no exceptional events. The play preparation part refers to the moving of the surrounding vehicles to some pre-specified positions and speeds that they will have when the next play starts. The play is a traffic situation that will be studied.

Janson Olstam and Espié (2007) present the play preparation problem using a theater metaphor, which is an extension of the theater metaphors 
presented in Alloyer et al. (1997), Espié and Rousseau (1998), and Wassink et al. $(2005,2006)$. The theater metaphor includes definitions of the terms play, manuscript, role, actor, stage, etc. in the context of a driving simulator experiment. A play in this context includes a manuscript and a role list and is performed on a stage. The manuscript defines the scenery (i.e. the road infrastructure, surroundings, road and weather conditions, etc.). The stage is defined as a limited area around the simulator vehicle which moves with the speed of the simulator vehicle. The role list is a description of all the main and walk-on characters. Each role includes a specification of the character's characteristics, e.g. vehicle type, brand and color. It also includes acting instructions, which define the driving behavior during the play. Last but not least, it includes a specification of the character's entering time and initial state, i. e. its position, speed, acceleration, etc. when the play starts. In this paper, the position and speed are specified as relative to the driving simulator vehicle, e. g. 400 meters ahead and $15 \%$ slower. There are both active roles and walk-on characters. The walk-on characters are here referred to as noroles. The no-role characters should not interfere with the main characters. Therefore, they are instructed to keep a minimum distance to the simulator vehicle. An actor is defined as a road user, e.g. a vehicle or pedestrian, that behaves or acts at some level of autonomy between "fully" controlled and "fully" autonomous. A "fully" controlled actor does not take any initiative and only follows the directives that it has been given. A "fully" autonomous actor on the other hand, takes initiatives and only considers a request from someone else if it complies with the actor's own goals. As proposed in Leitão et al. (2000), an actor's level of autonomy can vary within the simulation.

[Figure 1 about here.]

The three basic components (everyday life driving, play preparation, and plays) have different purposes in a driving simulator experiment. The plays are used to study driving behavior in some specific driving situation. The everyday life driving parts are used to get the subject to the awareness level, mood, etc. that he or she has in their normal everyday life driving in the current driving context. These parts are also used to "reset" the subjects between the plays. The play preparation is used to ensure that the plays start at the right time or at the right place and that the conditions at the start of the plays are comparable between subjects.

Driving simulator experiments have traditionally included either autonomous or controlled surrounding vehicles. The most common set up has been to use 
controlled surrounding vehicles both during everyday life driving and plays. The big advantage of this approach is that it makes it much easier to ensure reproducibility than using autonomous surrounding vehicles. The controlled vehicles' actions are defined from the simulator vehicle's point of view, e.g. oncoming vehicles are often set to meet the subject vehicle at a specific position. This makes it quite easy to create the same situation for each subject. The behavior of the autonomous vehicles is not defined from the subject vehicle's point of view. They treat the subject vehicle as any other vehicle. The driving conditions at a micro level will consequently depend on how the subject drives, i. e. as in real world driving. The traffic conditions will only be comparable at an aggregated level, i. e. flow, density, average speed, etc. Another advantage of using only controlled vehicles is that the play preparation is quite simple, since the scenario programmer has knowledge and control of all vehicles.

Autonomous vehicles are rarely used in driving simulator experiments due to the difficulties of ensuring an acceptable level of reproducibility. However, the requirement on reproducibility is generally lower during the everyday life driving parts than during the plays. Thus, during these parts it would be possible to use surrounding vehicles with a high level of autonomy without interfering with the demand on reproducibility. The suggestion is therefore to use a high level of autonomy in the modeling of everyday life driving to increase realism, and to use controlled vehicles during the plays to ensure reproducibility. The problem with this approach is that the play preparation becomes more difficult since the programmer does not have knowledge of where the surrounding vehicles are in advance. In this paper we will only consider the play preparation problem of going from autonomous everyday life driving to controlled directed plays.

\subsection{The play preparation sub-problems}

The play preparation problem can be divided into three sub problems: estimation of the start time of the play; casting; and transportation of actors. The transition from autonomous everyday life driving to a controlled play includes two trigger points, see Figure 1. The first point triggers the start of the play preparation and the second point triggers the hand over from the autonomous to the controlled mode. The start time estimation problem consists of estimating when the simulator driver will reach the second trigger point. The casting problem consists of finding actors that can play the roles in the upcoming play and assigning the roles to the most suitable actors. 
The transportation problem consists of moving each actor to the right initial position (either a role position or a no-role minimum distance) in a inconspicuous way. If there are no suitable actors on the stage, new ones have to be created out of sight of the simulator driver. The casting and transportation sub problems are strongly connected to each other and neither of the sub problems are trivial. The casting problem is difficult since the casting has to be done in such a way that the needs of transportation and reordering of actors are minimized. The transportation sub problem is difficult since the transportation of actors has to be done in a inconspicuous way. The total play preparation problem also has constraints regarding time and accuracy. The play preparation must result in the specified initial state of the play and it has to be completed before the play starts.

The casting sub problem can be summarized as a problem of finding the most suitable actor for each role. First of all, each role has to be filled by an actor that can play the role, i. e. that has the right characteristics and is able to reach the initial role position in time. The requirements for being able to play a role depends on if the actor currently is on the stage or not. Off stage (out of sight from the simulator driver), the actors are allowed to change characteristics (vehicle type, color, etc.). It is also possible to create or move actors in order to simplify the play preparation. However, on stage (within sight of the simulator driver), the actors are required to have the right characteristics and all movements have to be done in a inconspicuous way. In driving simulators an illusion of real driving is created. If some actors behave in a conspicuous (i.e. unexpected) way the illusion may break. One vague definition of a conspicuous action could consequently be an action that breaks the illusion. It is difficult to give a distinct and precise definition, but a conspicuous action is an action that differs from what you expect from a driver in a specific driving context and which make the subject aware of that something extraordinary is going to happen. An example of a conspicuous action is if a vehicle that you have caught up with and followed for a while, for no reason accelerates and speeds away from you. However, if the vehicle in front starts to accelerate after a preceding vehicle has turned off the road, the action is more plausible. The same action can be conspicuous or not depending on the context. How conspicuous an action is depends on the subject's earlier observations of the simulated driver's behavior and the action in relation to the driving context. For example, it is important that a simulated driver's changes in speed are consistent with the its behavior observed by the subject throughout the simulation. 
The transportation problem implies that an actor that is assigned a role has to reach the role's initial position and speed at the start of the play. This implies two constraints on the actor's speed trajectory. In order to reach the initial position, the actor has to travel at an average speed, $v_{a}$, which is dependent on the subject's future actions and especially on the speed of the simulator vehicle until the start of the play. The second constraint is that the actor's speed at the estimated play start time, $\hat{t}$, should be equal to the initial role speed, $v_{R}$. The problem of reaching the initial role position and speed can be described as:

Find a speed trajectory $v(t)$ which fulfills

$$
v(\hat{t})=v_{R}
$$

and

$$
\int_{0}^{\hat{t}}\left(v(t)-v_{a}\right) d t=0 .
$$

However, there are an infinite number of solutions to this problem and we want to find the "least conspicuous" solution. Let's study the following example: assume that there is an actor $1500 \mathrm{~m}$ behind the simulator vehicle with $v(0)=32 \mathrm{~m} / \mathrm{s}$ and that this actor should reach a role with an initial position $200 \mathrm{~m}$ behind the simulator vehicle and with $v_{R}$ equal to $9 \%$ higher than the speed of the simulator vehicle, see illustration in Figure 2. Further assumptions are that the simulator vehicle is expected to drive at a constant speed of $30.8 \mathrm{~m} / \mathrm{s}$ and that the estimated start time of the play $\hat{t}=180 \mathrm{~s}$. With these settings, the actor needs an average speed of around $38 \mathrm{~m} / \mathrm{s}$ in order to reach the initial role position. The number of possible speed profiles can be limited by taking into account knowledge of the highest acceleration and jerk levels used by drivers in normal driving. One possible speed profile (profile 1 in Figure 2) is to accelerate strongly up to a speed just above the required average speed and when getting close to the start time, decelerate strongly to the initial role speed. This profile implies the smallest changes and variation in speed but implies a large change in speed for a short time close to the driving simulator vehicle. This may be conspicuous if the speed change seems to happen without any plausible reason. An alternative speed profile (illustrated by speed profile 2 in Figure 2) is to accelerate more gently up to a speed higher than the required average speed and then use the achieved 
speed margin to smoothly regulate towards the initial role conditions. It is of course possible to do the opposite (profile 3 in Figure 2), but this approach does not seem to have any advantages, only disadvantages, like large changes in speed close to the simulator vehicle. The best strategy seems to be to accelerate or decelerate using normal utilized acceleration or deceleration rates to a suitable speed on the "right" side of the required average speed and then gently approach the initial role speed. A possible extension to the problem is to also put requirements on the initial role acceleration rate, or to specify if the acceleration should be less than, equal to, or larger than 0 . Speed profile 4 (in Figure 2) shows an example in which the vehicle reaches the initial role speed with a small positive acceleration.

[Figure 2 about here.]

\section{Algorithm}

The developed algorithm consists of three phases, which are related to the estimation of the play start time, the casting, and the transportation of actors. Figure 3 shows how the algorithm is working in each simulation time step. An initial casting is done when trigger 1 is reached. The play start time estimation, the transportation part, and a check that actors still can reach their assigned role, are run in each time step of the simulation. The "able to reach role" control is currently only done for actors that are assigned a no-role, but should in future development also include active roles.

[Figure 3 about here.]

The following sections will describe the three phases of the algorithm in more detail. The play start time estimation is described in Section 3.1, the casting in Section 3.2 - 3.3, and the transportation algorithm in Section 3.4 -3.8 .

\subsection{Estimation of the start time of a play}

Both the casting algorithm and the transportation algorithm need an estimate of the available time for finishing the play preparation. Estimating the play start time $\hat{t}$ (equal to the arrival time of the simulator vehicle) consists of estimating the simulator driver's average travel speed until the 
simulator driver reaches the second trigger point. This average travel speed can be estimated as

$$
\hat{v}_{D S}=\alpha \cdot v_{D S}+(1-\alpha) \cdot \hat{v}_{D S}^{d e s}
$$

where $v_{D S}$ is the current speed of the driving simulator, $\hat{v}_{D S}^{\text {des }}$ is the estimated desired speed of the simulator driver (estimated according to the procedure described in Janson Olstam et al. (2008)). The parameter $\alpha$ is a weighting factor based on the distance to the second trigger point calculated as

$$
\alpha=\max \left\{0,1-\frac{1}{d_{\max }} \cdot\left(x_{p l a y}-x_{D S}\right)\right\},
$$

where $d_{\max }$ is a calibration parameter currently set to $2000 \mathrm{~m}, x_{\text {play }}$ is the start position of the play, and $x_{D S}$ is the current position. When the distance to the next play is large, the estimate of the space mean speed will mainly be influenced by the estimated desired speed. Drivers normally drive with a speed less than or equal to their desired speed, thus the arrival time may be underestimated but seldom overestimated. The closer to the start point of the play the simulator driver gets, the more reliable the current speed will be as an estimate, and $\hat{v}_{D S}$ will approach the current speed as the distance approaches zero.

\subsection{Casting of active roles}

When the first trigger point has been reached, the play preparation starts with the casting of the roles in the role list. The roles closest to the simulator vehicle could in some sense be compared to the leading actors of the play and consequently it is most critical to find suitable actors for these roles. The casting algorithm therefore starts with the casting of the roles closest to the simulator vehicle and then continues with the ones further away. The casting of a role is a process in which actors are evaluated one at a time. The procedures for the casting of actors behind and in front of the simulator vehicle are equivalent. The procedure for the casting of roles behind the simulator vehicle are done according to the following algorithm

0. Set the role-to-be-assigned equal to the closest role behind the simulator vehicle and go to step 1.

1. Set the actor-to-be-evaluated equal to the closest actor behind the simulator vehicle and go to step 1 a. 
(a) Check if the actor-to-be-evaluated is already assigned a role.

If so, go to step 2. Otherwise go to step $1 b$.

(b) Check if the actor-to-be-evaluated can play the role.

If so, go to step 1c. Otherwise go to step 2.

(c) Check if the actor-to-be-evaluated can reach the stage in time. If so, go to step $1 d$. Otherwise go to step 2.

(d) Check if the actor-to-be-evaluated is the most suitable actor for the role so far. If so, assign the role to the actor-to-be-evaluated and un-assign the role from any previously chosen actor. Go to step 2.

2. Check if there is any actor behind the actor-to-be-evaluated on the stage. If so, set the actor-to-be-evaluated equal to the actor behind the current actor-to-be-evaluated and go to step 1a. Otherwise, go to step 3.

3. Check if no actor fulfills the requirements or if it is more suitable to create a new actor off stage. If so, create a new actor from off the stage and assign the role to this actor and un-assign the role from any previously chosen actor. Go to step 4.

4. Check if there is a role behind the current role. If so, set the role-to-beassigned to this role and go to step 1. Otherwise, end the assignment loop.

The following sections will describe steps $1 \mathrm{~b}-1 \mathrm{~d}$ in more detail.

\subsubsection{Step $1 b$ - Can the actor play the role?}

If the role characteristics include a specification of vehicle type or brand, the actor has to match the requested type and/or brand in order to be able to play the role. Other constraints are that actors who have been passed by the driving simulator vehicle are not allowed to play faster roles behind the simulator vehicle and actors that have passed the driving simulator vehicle are not allowed to play slower roles in front of the simulator vehicle. Faster and slower roles are defined as roles that, at least initially, are set to drive faster or slower than the subject, respectively.

\subsubsection{Step 1c-Can the actor reach the stage in time?}

Whether an actor can reach the initial role position in a inconspicuous way or not, depends on the average travel speed needed to reach the role and how much the actor can change speed without acting in a conspicuous way. The required average speed is calculated as

$$
v_{a}=\hat{v}_{D S}+\frac{\Delta x_{R}-\Delta x}{\hat{t}-t}
$$


where $\hat{v}_{D S}$ is the estimated average travel speed of the simulator driver according to equation $3, \hat{t}$ is the estimated start time of the play, $t$ is the current time, and $\Delta x$ and $\Delta x_{R}$ are the current and initial role distances to the simulator vehicle, respectively. The difficult part is to estimate if an actor can achieve this average speed in a inconspicuous way. How much an actor can change speed (or rather his desired speed) without acting conspicuously depends on how fast this actor has been observed to drive (from the simulator driver's point of view). An actor is assumed to be able to reach a role if

$$
\gamma \cdot v^{o b s}<v_{a} \text { for } \Delta x_{R}-\Delta x<0,
$$

and

$$
\eta \cdot v^{\text {des }}>v_{a} \text { for } \Delta x_{R}-\Delta x>0,
$$

where $v^{o b s}$ is the fastest speed the actor has been driving at on the stage, $v^{\text {des }}$ is the actor's desired speed, and $\gamma$ and $\eta$ are calibration parameters currently set to 0.9 and 1.1 respectively. This means that the slowest speed an actor is assumed to be able to drive at without decreasing speed too much with respect to conspicuity is equal to $90 \%$ of the fastest speed the actor has been observed to drive at on the stage. In the same way an actor is assumed to be able to drive at most $10 \%$ faster than her desired speed without acting conspicuously.

\subsubsection{Step 1d - How suitable is the actor for this role?}

The most difficult part of the casting is to evaluate how suitable a specific actor is for a specific role. In terms of the longitudinal transportation problem the task can be described as: for each role, find the actor with the least conspicuous speed profile. A really good and precise casting algorithm should also try to find the combination of actors and roles that minimize some kind of total conspicuity (see discussion in Janson Olstam and Espié (2007)). However, the algorithm is going to be used in a real-time running program and the computer time needed for evaluating one actor for a role has to be kept as low as possible, thus the problem is to find a good feasible solution rather than the optimal one. For the casting, we need a criteria that evaluates the conspicuity of the changes in speed and acceleration that each actor will have to apply to reach the role's initial position and speed, if they are assigned this role. The criteria utilized, is not based on extensive research and is a focus for further research. However, it worked well during the test conducted 
within this work. The following equation has been used to quantify how suitable an actor is for playing a specific role $R$ :

$$
Z=\left|\frac{1}{\left(v_{a}-v\right)^{c_{1}}}+\frac{1}{\left(v_{R}-v_{a}\right)^{c_{1}}}\right| \cdot\left(c_{2} \cdot\left|\Delta x_{R}-\Delta x\right|+c_{3} \cdot n_{v}\right),
$$

where $v_{a}$ is the required average speed according to equation $5, v_{R}$ is the initial role speed, $v$ is the actor's current speed, $n_{v}$ is the number of vehicles between the actor and the simulator vehicle, $\Delta x$ and $\Delta x_{R}$ is the current and initial role distance to the simulator vehicle, respectively, and $c_{1}, c_{2}$, and $c_{3}$ are parameters. The parameter $c_{1}$ should be equal to an odd positive integer value. To avoid division with zero a minimum value is required for the two denominators.

The values of $Z$ given from equation 6 are not interpretable but are useful for comparing the suitability of different actors for a specific role. The part $\left|\frac{1}{\left(v_{a}-v\right)^{c_{1}}}+\frac{1}{\left(v_{R}-v_{a}\right)^{c_{1}}}\right|$ of equation 6 is designed to capture that it is preferable if an actor can reach the required relative position and speed with as few and as small speed changes as possible. The suitability criteria favor combinations of actors and roles in which the actor's current speed and the initial role speed are close to the required average speed. It is also preferable if the actor's current speed is not on the same side of the required average speed as the initial role speed. This is captured by using an odd positive integer value on the parameter $c_{1}$.

At first glance, it may seem to be preferable that the actor is approximately at the required relative position. However, this is only true if the difference between the current speed and the required average speed and the difference between the required average speed and the initial role speed is small. Otherwise, being at the approximately right position from the beginning will imply that the actor has to go away from this relative position and then come back at another speed in order to be able to reach both the initial role speed and position. Another aspect is that the conspicuity requirement should be higher for vehicles close to the simulator vehicle. The actions of an actor that are several actors away from the simulator vehicle are generally not as observable as the actions of the actor just in front of the simulator vehicle. These factors are captured by the terms $c_{2} \cdot\left|\Delta x_{R}-\Delta x\right|$ and $c_{3} \cdot n_{v}$ in equation 6 , which imply that the requirements on the speed difference decreases with increasing distance difference and with an increasing number of vehicles between the actor and the simulator vehicle, respectively. 
The parameters have not undergone any extensive calibration but $c_{1}=3$, $c_{2}=0.05$, and $c_{3}=2$ have proven to work well and no apparently bad role casting has been observed in the conducted experiment.

\subsection{Assignment of no-roles}

The actors that are not assigned any active role are assigned a no-role. These actors are instructed to achieve and maintain a specified minimum distance to the simulator vehicle. An actor can either be assigned a no-role behind or in front of the simulator vehicle. If the simulated road includes ramps or intersections, the no-roles can also be specified as exiting the road at an intersection. The actor's should be assigned the no-role that leads to the least conspicuous transportation from the simulator driver's point of view. This is generally the no-role on the same side of the simulator vehicle as the actor, e. g. an actor behind the simulator vehicle is in general assigned the norole behind the simulator vehicle. The difficulties in the no-role assignment have to do with actors driving relatively close to the simulator vehicle. The approach developed estimates whether or not an actor behind the simulator vehicle will be able to catch the simulator vehicle and whether or not an actor in front will be caught by the simulator vehicle within half of the preparation time. For example, an actor in front of the simulator vehicle will be assigned a no-role behind if

$$
\hat{t}_{\text {catch }}<0.5 \cdot(\hat{t}-t)
$$

where

$$
\hat{t}_{\text {catch }}= \begin{cases}\frac{x-x_{D S}}{\hat{v}_{D S}-v}, & \text { for } \hat{v}_{D S}>v \\ \infty, & \text { otherwise. }\end{cases}
$$

These conditions are also used to continuously test if an actor that is assigned a no-role can still reach this role or if he/she has to be assigned another norole, in the "able to reach role" algorithmic step in Figure 3.

\subsection{Longitudinal transportation strategy for active roles}

For the longitudinal transportation of actors that are assigned active roles, a strategy corresponding to speed profile 2 in Figure 2 is chosen. The actor's strategy is to reach a speed on the necessary side of the required average speed, i. e. the side opposite to the initial role speed. The actor can then smoothly regulate towards the initial role speed. The acceleration that an actor applies in order to reach an assigned role is calculated as

$$
a= \begin{cases}\frac{v_{a}-v}{t_{c}}, & \text { if } \operatorname{sign}\left(v-v_{a}\right) \neq \operatorname{sign}\left(v_{R}-v_{a}\right) \text { and } t_{c} \leq 0.5 \cdot \tilde{t} \\ \frac{v_{a}-v_{R}+v_{a}-v}{0.3 \cdot \tilde{t}}, & \text { otherwise, }\end{cases}
$$


where

$$
t_{c}=\frac{v_{a}-v_{R}}{v-v_{R}} \cdot \tilde{t}
$$

Here $v$ is the current speed, $v_{a}$ is the required average speed, $v_{R}$ is the initial role speed, the function $\operatorname{sign}(x)$ gives the sign (negative or positive) of $x$, and $\hat{t}$ is the estimated time left to the play, i. e. $\tilde{t}=\hat{t}-t$. The time $t_{c}$ is the time at which the actor should pass the required average speed in order to fulfill the conditions given by equation 1 and 2, given that constant acceleration rates are used. The time $t_{c}$ can easily be derived, using Figure $4 \mathrm{a}$, from the condition that the area of the triangle above the required average speed has to be equal to the area of the triangle below. The condition can mathematically be described as

$$
\frac{t_{c} \cdot\left(v-v_{a}\right)+\left(\tilde{t}-t_{c}\right) \cdot\left(v_{R}-v_{a}\right)}{2}=0 .
$$

[Figure 4 about here.]

If the actor is on the less suitable side of the required average speed, see example in Fig. 4b, the actor will try to reach a speed equal to $v_{a}-\left(v_{R}-v_{a}\right)$ within $30 \%$ of the remaining time of the preparation, see the second case in equation 9. The final acceleration given by equation 9 is checked and if necessary, adjusted so that it does not violate requirements for maximum acceleration and jerk or any deceleration due to a car-following situation with a preceding vehicle.

\subsection{Longitudinal transportation strategy for no-roles}

Actors that are assigned no-roles use a straightforward and rather simple strategy to transport themselves off the stage and to the specified minimum distance to the simulator vehicle. Actors that have not yet reached the minimum distance to the simulator vehicle simply decrease or increase their desired speed to the necessary level. In this way, only the actor's driver characteristics are changed and there is no need for changes in the underlying behavioral models for acceleration, lane-changing, etc. If the underlying behavioral models give realistic driver behavior, the conspicuity regarding the remove transportation should not be a problem. In order to avoid conspicuously quick changes in speed, the actors are only allowed to change their desired speed by $3 \mathrm{~km} / \mathrm{h}$ per second. Actors that have reached the minimum distance will gradually change their desired speed towards the speed of the 
simulator vehicle, in order to keep at least the minimum distance, and at the same time, not go too far away from the simulator vehicle. In cases when the desired speed is temporarily increased, the vehicle's acceleration capability may also have to be temporarily adjusted so that the actor can reach the new desired speed.

\subsection{Lane changing strategy}

The basic idea behind the transportation algorithm is that the actors should as much as possible act according to their underlying behavioral models. However, it is sometimes necessary for the actors to deviate from their normal behavior in order to reach their assigned role or to help other actors to reach their roles. It is sometimes preferable to not make a desired lane change. This can be for example if the actor in front is assigned a role in front of the current actor or if by changing lane the actor will go away from the specified initial role lane. Sometimes, it can also be preferable to change lane even if the actor normally does not estimate this lane change as desirable or necessary. This can be for example if the actor in front is assigned a role behind or if the actor's current lane differs from the initial role lane.

\subsection{Actor collaboration}

To simplify the rearranging of the actor sequence and to decrease the risk for conspicuous actions, the actors are instructed to collaborate. The primary goal of an actor is of course to reach his initial role conditions but the actor should as much as possible try to help the surrounding actors in their striving to reach their roles. For example, an actor can send a request to a preceding actor that is assigned a role behind him to change lane to the right or keep to the right so that the actor can pass. Actors trying to reach a no-role in front are often constrained by other no-role actors that have already reached the minimum distance. These actors can be asked to accelerate in order to make it easier for the actors that have not yet reached the minimum distance. Another example of collaboration is that actors that need to change lane, either in order to reach their initial role position or to let someone else pass, can ask the actors in the target lane to increase the gap if it is too small.

In the implementation, the actors can send three different requests to each other; asked-to-decelerate, asked-to-accelerate, and asked-to-change-lane. The asked-to-decelerate request is currently only sent when more space for a lane change is needed. The receiver of the request will decelerate if the receiver 
does not need to accelerate in order to reach it's own role. Conflicting deceleration and acceleration requests are handled in a simplistic way, acceleration requests are only considered if there are no deceleration requests. In the current implementation, only no-role actors will consider deceleration and acceleration requests from other actors. An actor that receives an acceleration requests will try to accelerate faster if it already wants to accelerate or if it is the desired speed that limits the acceleration, to temporarily increase it's desired speed. If the actor normally would have decelerated due to interactions with a vehicle in front, the actor will forward the request to it's leader vehicle. The handling of lane change requests is more complicated. The actor will compare the initial positions of its own role and the surrounding actors' role. The actor will try change lane so that actors with initial role positions in front of the own initial role position can pass. Although the implemented actor collaboration seems to work quite well, it would probably gain on further development towards a more generic and structured approach for handling requests and request conflicts.

\subsection{Re-transition after finished event}

After a completed play preparation the actors with active roles will start to behave according to the manuscript and the actors with no-roles will play their walk on characters in the periphery, by keeping the specified minimum distance to the simulator vehicle. When the play is finished, the surrounding traffic should change back to autonomous mode. At the end of a play, the stage includes only those actors that were assigned active roles in the finished play. If the number of active roles is few, the area around the simulator vehicle will be more or less empty since the no-role actors have been forced away from this area. It will take some time before the no-role actors catch up with or are caught up by the simulator vehicle. In order to speed up the re-transition to autonomous surrounding traffic the no-role actors are asked to temporarily decrease (actors in front) or increase (actors behind) their desired speeds.

\section{Algorithm Evaluation}

A driving simulator experiment has been conducted in order to test the developed algorithm. The aim was to test if the algorithm is able to reconstruct equal play start conditions for each subject in a inconspicuous way. The aim was also to test if the type of traffic (autonomous or controlled) 
during the everyday life driving affects the subjects' driving behavior and/or experience of the drive. One hypothesis was that subjects will drive faster in the presence of the kind of controlled everyday life traffic that has been used on freeways in the VTI driving simulator III than they normally do.

\subsection{Testbed}

The algorithm developed has been implemented in the traffic simulation framework for surrounding vehicles in driving simulators presented in Janson Olstam et al. (2008). However, the car-following and lane changing models used in Janson Olstam et al. (2008) have been replaced by versions of the HDM/IDM car-following model (Treiber et al., 2000, 2006) and a combination of the ARCHISIM (El Hadouaj and Espié, 2002) and the MOBIL (Kesting et al., 2007) lane-changing models. The lateral position update algorithm has been replaced by the steering model presented in Salvucci et al. (2001). The simulation framework has been integrated with and tested in the VTI driving simulator III (VTI, 2008). This driving simulator is a vehicle cabin and motion based driving simulator with a 120 degree field of view in front and three back mirrors.

\subsection{Scenario description}

The scenario consisted of three plays along a $72 \mathrm{~km}$ long freeway stretch. The speed limit was $110 \mathrm{~km} / \mathrm{h}$ and there were two lanes in each direction; see Figure 5 for an illustration. There were on- and off ramps along the road but no entering or exiting vehicles. The road was dry but there was some mist in the air.

[Figure 5 about here.]

The scenario started with a $10 \mathrm{~km}$ long warm-up section without any surrounding traffic. It continued with a $15 \mathrm{~km}$ long section with controlled everyday life traffic followed by a $15 \mathrm{~km}$ long part with autonomous everyday life traffic. The traffic during the controlled everyday life part was designed in the same way as in earlier freeway experiments in the VTI driving simulator, e.g. the DIWITSA project (IVSS, 2008). The controlled everyday life traffic was defined so that the number of active and passive catch ups that the subjects experienced would be the same for all subjects. This implies that there would be vehicles driving faster and slower than the subject independent of how fast or slow the subject drove. The controlled everyday life 
traffic consisted of nine catch up situations, in which the subject caught up with a slower vehicle platoon. In six of the cases, a faster vehicle platoon arrived in the left lane at the same time. The subject then had to decide whether or not to change lane and overtake the slower platoon or to let the faster platoon pass first. The platoons were added to the simulation out of sight of the subject. Their speed is then regulated in order to get into interaction with the subject at some specific point in space and time. In order to get them quickly within sight and closer to the subject, their speeds sometimes need to be quite extreme, e.g. over $200 \mathrm{~km} / \mathrm{h}$ or $0 \mathrm{~km} / \mathrm{h}$, depending on relative position to the subject. The number of vehicles in each platoon in the nine situations is presented in Table 1.

\section{[Table 1 about here.]}

The traffic conditions during the autonomous everyday life driving part are defined in terms of flow and vehicle type shares, in this case set to 1200 vehicles/h/direction and $92 \%$ cars, $6 \%$ trucks and $2 \%$ buses. The $15 \mathrm{~km}$ long autonomous everyday life driving part is followed by the first play preparation and play. The play consists of a $1 \mathrm{~km}$ stretch with dense fog in which no surrounding vehicles should be closer to the subject than 300 meters. The reason for using this kind of low complexity play is to test the remove transportation of no-role actors separately. For the first play, the play preparation is set to start $1 \mathrm{~km}$ upstream of the play. This play is followed by $10 \mathrm{~km}$ of autonomous everyday life driving and an identical play, but now with $2 \mathrm{~km}$ of play preparation. This makes it possible to investigate how the length of the play preparation time affects the algorithm's ability to achieve the play start condition. The preparation of the third and last play starts after another 10 $\mathrm{km}$ of autonomous everyday life driving. The preparation time for this play is $2 \mathrm{~km}$. This play includes four active roles. The leading star role is a car in front of the subject that after some driving, has a car break down and has to decelerate and park on the shoulder. At the same time, and in order to prevent the subject from immediately changing lane the subject is passed by a platoon of three vehicles. The start condition for the front car is a relative position of $400 \mathrm{~m}$ and a relative speed of 0.78 . The start conditions for the three cars behind are relative positions of $250 \mathrm{~m}, 300 \mathrm{~m}$, and $350 \mathrm{~m}$, and a relative speed of 1.15. The no-role actors should have a minimum distance of $400 \mathrm{~m}$ to the subject. 


\subsection{Post-questionnaire and interview}

A post-questionnaire was designed to deal with questions regarding background data and driving style. Also, the general impression of the simulator drive was examined with regards to steering, accelerating, braking, perception of speed, perception of lateral position and overall impression of the simulator. These questions on the simulator drive concerned perceived similarities between driving a simulator and driving a real car. There are wellknown questionnaires that deal with presence in a simulated environment (see e.g. Witmer and Singer, 1998; Usoh et al., 2000). Those questionnaires focus on the individuals feeling of being in a simulated environment although physically present in another. These aspects are somewhat related to realism but concerns a slightly different aspect of the simulator experience than what was the purpose of the present study. The intention of the post-questionnaire was twofold, firstly to let the subjects elaborate on the simulator experience. This was important in order for the test leader to have the subject focus on the research related questions that were separate from the experience of driving a simulator vehicle, in our case, the surrounding traffic. Secondly, the questions in the post-questionnaire have been used in previous studies in the same simulator, hence allowing us to confirm that the driving experience in the present study did not deviate in a significant way from other simulator studies performed (Janson Olstam, 2005; Janson Olstam et al., 2008). If it was concluded that the drive was normal regarding the simulator experience, we could leave that aspect of the study and focus on the research questions at hand.

The design of the interview comprised an interview guide with open questions and a sketch of the outline of the drive. The interview concerned the traffic situation and the behavior of the surrounding vehicles during the different parts of the drive. The subjects were asked questions regarding their general impression of the drive, questions related to the different parts of the drive, i. e. the first fog, the second fog and the car that surprisingly stopped at the end of the drive. The sketch of the outline of the drive was used as a mnemonic device. The outline was similar to the one in Figure 5 (without the information on controlled and autonomous traffic). The outline was also used as a support for the subjects to place their observations in time and space. The subjects' impression of the traffic situation during the period (play preparations) just before the first and second fog and the car break down was also discussed. The interviews were taped and transcribed for further analysis. Both the post-questionnaire and the interview guide are 
available upon request.

\subsection{Subjects and experiment procedure}

The ten subjects' gender, age, number of years with driving license, mileage driven last year, number of drives in the VTI driving simulator, and their self-reported normal/desired speed on freeways are presented in Table 2 .

[Table 2 about here.]

All subjects were in-house VTI personnel with no previous insight into or knowledge of this particular study. Upon arrival at the simulator facility, the subjects were directly asked to take a seat in the driver seat of the simulator. The subjects were told that they would drive on a freeway with a speed limit of $110 \mathrm{~km} / \mathrm{h}$ for approximately 40 minutes and that the first $10 \mathrm{~km}$ was a warm-up stretch without any surrounding vehicles. The subjects did not get any further instructions but were asked to drive as they normally would on a similar freeway. During the whole simulator drive, the test leader took notes on traffic situations or driving behavior that deviated from the test leader's expectations of realistic traffic situations and driving behavior. The main focus was the behavior of the surrounding vehicles during the play preparations.

After the drive, a post-questionnaire was filled in (see Section 4.3) and the subjects were interviewed by a trained psychologist (co-author S. M.). The interviews were taped and transcribed for further analysis. Both the post-questionnaire and the interview guide are available upon request.

\subsection{Results}

\subsubsection{Actors' ability to reach roles and no-roles}

The main aim of the driving simulator experiment was to test if the algorithm was able to reconstruct the same play start conditions for all subjects. At the end of each play preparation, the actors' position, speed, etc. were measured and compared to the role specifications. The no-roles only included a specification of the minimum distance to the driving simulator vehicle (300 $\mathrm{m}$ for play 1 and 2 and $400 \mathrm{~m}$ for play 3 ). Table 3 - Table 5 display the distance between the subject and the first no-role actor in front and behind the subject. In connection with play 1 (Table 3 ), the minimum distance was always reached by the actors behind the simulator vehicle, while the 
actors in front only succeeded in two of the cases. For play 2 (Table 4 ), the minimum distance was reached more or less in all cases with some exceptions and the situation was similar for play 3 (Table 5). The difference between plays 1 and 2 can most likely be explained by the difference in preparation time.

[Table 3 about here.]

[Table 4 about here.]

[Table 5 about here.]

Play 3 also included active roles. The difference between the achieved distance and the specified distance to the subject for each active role is presented in Table 6 . The difference is less than 1 meter for all subjects and roles. These small differences are within acceptable limits.

[Table 6 about here.]

Besides the relative position, the active roles also included a specification of the relative speed to the driving simulator vehicle, specified as $\frac{v_{R}}{v_{D S}}$. The difference in percent units between the achieved relative speed and the specified relative speed, i. e. $100 \cdot\left(\frac{v}{v_{D S}}-\frac{v_{R}}{v_{D S}}\right)$, is presented in Table 7 . The difference is less than 0.5 percent units, i. e. less than $0.15 \mathrm{~m} / \mathrm{s}$ at $30 \mathrm{~m} / \mathrm{s}$, for all experiment runs except for the runs with subjects 1,7 , and 9 . For the experiment runs with subjects 1,7 , and 9 the differences are of the magnitude 2 - 5 percent units, i. e. less than $1.5 \mathrm{~m} / \mathrm{s}$ at $30 \mathrm{~m} / \mathrm{s}$, which is less good but still workable. The conclusion is that the speed differences are within acceptable limits.

[Table 7 about here.]

\subsubsection{Subject's mean free speed}

The hypothesis regarding the subjects' speed choice is that the subjects drive faster in the presence of controlled everyday life traffic than they normally do. The assumed reason for this is that they feel pressured by the fast cars coming from behind. These cars will drive faster than the subject independent of how fast the subject drives (the faster the subject drives, the faster will the vehicles behind drive). An example of the difference in 
the surrounding vehicles' speeding behavior during the different everyday-life driving parts is presented in figure 6. The figure shows the effect on vehicle speeds when forcing vehicles to catch-up or be caught by the simulator vehicle as is the case during the controlled everyday life driving part. The effect is that there are both extremely fast and slow vehicles and thereby a large variation in speed during the controlled everyday life driving part. This can be compared to the low speed variation during the autonomous everyday life driving parts. In the figure the play situations can easily be localized. The acceleration and deceleration of the surrounding autonomous vehicles in order to reach the no-roles in front and behind the simulator vehicle could also be identified. Apparently, some vehicles had to drive quite fast/slow in order to reach the no-roles.

[Figure 6 about here.]

To examine the hypothesis, the average driving speed of subjects during periods of free driving was compared across conditions (controlled vs. autonomous traffic). Free driving was operationally defined as periods during which time headway $>6 \mathrm{~s}$ and $\mid$ acceleration $\mid<0.5 \mathrm{~m} / \mathrm{s}^{2}$. Table 8 presents the subjects' mean free speed during the warm-up, controlled and the three autonomous parts while Table 9 presents the difference in the subjects' mean free speed between the controlled part and the warm-up part and the three autonomous parts, respectively. The difference is generally positive and varies from -0.32 to $4.64 \mathrm{~m} / \mathrm{s}$.

\section{[Table 8 about here.] \\ [Table 9 about here.]}

One sided t-tests have been conducted with the hypothesis that the subjects' mean free speed during the controlled part is higher than during the warm-up part and the three autonomous parts. This gives four t-tests: controlled - warm-up; controlled - autonomous 1; controlled - autonomous 2; and controlled - autonomous 3. Table 10 shows the t-statistics from the four t-tests. The difference in mean free speed is significant at the $95 \%$ confidence level for all tests. The conclusions are that the subjects drive about $1 \mathrm{~m} / \mathrm{s}$ faster during the controlled everyday life driving part than during the autonomous everyday life driving parts and than during the warm-up period.

[Table 10 about here.] 


\subsubsection{Subject comments and test leader observations}

In this section, the results from the interviews and observations made by the test leader are summarized. The test leader observed some problems with the casting and transportation of no-role actors. The problems were mainly related to the transportation of actors that are close to the simulator vehicle when the play preparation starts. The problems seem to be more severe in connection with the shorter preparation time of $1 \mathrm{~km}$. There were for example, situations in which an actor in front of the subject had been assigned a no-role behind the subject and therefore started to decrease her speed in order to give the subject a reason to pass. However, the decrease seemed to be too rapid and the subject observed the change as a strong deceleration and started to decelerate instead of changing lane. This sometimes resulted in the actor no longer thinking that the subject would catch up with him/her. The actor would then be re-cast into a no-role in front, and thereby start to accelerate. This may have been a problem of inconsistency in the no-role casting, i. e. that the casting of a no-role changed back and forth from a no-role behind and a no-role in front. Unfortunately, there was no recording of data regarding the changes in no-role casting during the experiment. In the agent literature this kind of problem is called dithering and commonly results when action selection algorithms operate near a decision threshold. One reason for the problem in this case could be bad tactical behavior in the no-role transportation model. One solution to reduce dithering could be to add hysteresis to the decision making process so that once a decision is made, the threshold shifts so that it takes a more substantial change in circumstance to change the outcome. For the no-role casting that could be done by using a different threshold than 0.5 in equation 7 for the continuous "able to reach role" algorithmic step in Figure 3. An additional reason for the dithering problems may have been that the maximum allowed speed change of $3 \mathrm{~km} / \mathrm{h}$ per second was too high.

Half of the subjects commented on the catch up situations during the controlled everyday life traffic in which the subject caught up with a slower platoon at the same time as a fast vehicle platoon caught up with the subject. Some subjects gave comments like "The overtakings were not normal" or "These situations happen more often than in real traffic". One subject also commented on the fact that he drove faster than he normally does due to the fact that the other vehicles drove fast. Other comments did not include any value judgment. However, the fact that these traffic situations were 
commented on indicates that these situations, or their frequent appearance, differ from real freeway traffic.

Three of the subjects thought that the autonomous everyday life traffic drove slower than real world freeway traffic, leading to too many active catchups and too few passive catch-ups. Two of the subjects also thought that the autonomous traffic was calmer than real traffic and that there were too few really fast and aggressive drivers. The test leader observed that the autonomous vehicles never, or seldom, were able to reach their desired speed. The reason for this was found to be the design of the IDM car-following model (Treiber et al., 2000), more precisely, the function for calculating acceleration due to interactions with a preceding vehicle. The observed deficiency leads to a lower average speed than what is expected for a specific distribution of desired speeds. This is probably one explanation to why the subjects thought that the autonomous vehicles drove slowly. The problems with the IDM model have been further investigated and solved in Olstam and Tapani (2010).

There were observations about autonomous cars that passed the simulator driver really slowly or vehicles that did not seem to be able to decide if they should pass or not. The autonomous vehicles were sometimes considered to drive irregularly, i. e. change speed without reason. These observations seem to be in connection with play preparations. Some strange lane changes and speed changes were observed during the play preparations. Some of the observations may concern situations during autonomous everyday life traffic. Several subjects observed that there was no or little traffic around them when they entered the foggy parts.

\section{Conclusions and future research}

In the present paper, an algorithm for combining autonomous surrounding traffic and controlled events is presented. The algorithm has been tested in the VTI driving simulator III with promising results. In most of the cases the algorithm could reconstruct the specified start condition and conduct the transition from autonomous to controlled mode in a inconspicuous way. However, some problems were observed, for example regarding transporting no-role actors to the specified minimum distance to the subject. Since the algorithm only has been tested on 10 subjects, two types of plays, one traffic condition, etc. it is difficult to make general conclusions. However, for the driving simulator experiment conducted the conclusions are the following: 
- The casting and transportation of active roles works satisfactory, but the underlying algorithms are still topics of future research.

- The casting and transportation of no-roles do not always work as intended. This part has to be enhanced in order to ensure reproducibility.

- The platoon situations that frequently appeared during the controlled everyday life traffic were considered different to real freeway traffic situations as expressed by half of the participating subjects. The behavior of the surrounding vehicles during this part had a significant effect on the subjects free driving speed, which was higher than during autonomous everyday life traffic and during warm-up without any traffic.

- Three subjects experienced the autonomous everyday life traffic as slower and calmer than real freeway traffic. In addition, two subjects thought that there were too few really fast and aggressive drivers as compared to driving in a real traffic environment.

- The underlying autonomous behavior models have to be enhanced with regard to the problems observed with slow overtakings, strange lanechanging behavior and vehicles that are not able to reach their desired speeds.

The conclusions from the experiment strengthens the hypothesis that it is possible to gain in realism without losing too much in reproducibility by combining autonomous and controlled simulated road users. In most of the cases the algorithm could reconstruct the specified start condition, i. e. ensure the required reproducibility. The interviews and the measures of free speed during controlled and autonomous everyday life traffic indicates that autonomous traffic can be used to get a more realistic description of traffic conditions along a freeway.

The problem with the transportation of no-role actors is more severe in connection with the shorter preparation time of $1 \mathrm{~km}$. It seems that $1 \mathrm{~km}$ preparation time is too short for clearing an area of 300 meters around the subject at a traffic flow of 1200 vehicles/h. One solution could be to use a variable preparation time that depends on the current traffic situation around the simulator vehicle.

The algorithm has only been tested for two types of plays and for one traffic condition. Further tests with different kinds of plays, start conditions, and 
traffic conditions (especially more dense conditions) are needed. The algorithm should also be tested within a "real" driving simulator experiment and not only in an experiment designed to test the algorithm. In order to investigate the algorithm's independence with respect to choice of driving simulator and simulation model, the algorithm should be tested with another model for the simulation of the autonomous vehicles and in other driving simulators. However, before any additional testing is done the problems observed regarding casting and transportation of no-role actors have to be solved. Further research should also include enhancements of the IDM car-following model which was found to have deficiencies regarding the calculation of interaction accelerations.

\section{Acknowledgements}

This work was funded by the Swedish Road Administration, Transport Telematics Sweden and INRETS. The authors would like to thank the reviewers for their insightful and constructive comments and Laban Källgren (VTI) for his priceless help with the integration with the VTI Driving Simulator III and the scenario programming.

Al-Shihabi, T., Mourant, R. R., 2002. Toward more realistic driving behavior models for autonomous vehicles in driving simulators. In: Proceedings of the 82nd Annual Meeting of the Transportation Research Board. Washington, D.C., USA.

Alloyer, O., Bonakdarian, E., Cremer, J., Kearney, J., Willemsen, P., 1997. Embedding scenarios in ambient traffic. In: Proceedings of the Driving Simulation Conference, DSC'97. Lyon, France.

Cremer, J., Kearney, J., Papelis, Y., 1995. HCSM: A framework for behavior and scenario in virtual environments. ACM Transactions on Modeling and Computer Simulation 5 (2), 242-267.

El Hadouaj, S., Espié, S., 2002. A generic road traffic simulation model. In: Proceedings of the ICTTS (Traffic and transportation studies). Guilin, China.

Espié, S., 1995. ARCHISIM: Multiactor parallel architecture for traffic simulation. In: Proceedings of the 2nd congress on Intelligent Transport Systems'95. Yokohama, Japan. 
Espié, S., Rousseau, G., 1998. Experimental protocols description language for driving simulators. In: Proceedings of the EURISCON \& SOFTCOM'98. Athens, Greece.

IVSS, 2008. Projects within the ivss programme. http://www.ivss.se/ templates/Page. aspx?id=139, accessed September 11, 2008.

Janson Olstam, J., 2005. A model for simulation and generation of surrounding vehicles in driving simulators. Licentiate thesis, Linköpings universitet, liU-TEK-LIC 2005:58.

Janson Olstam, J., Espié, S., 2007. Combination of autonomous and controlled vehicles in driving simulator scenarios. In: Proceedings of Road Safety and Simulation (RSS2007). Rome, Italy.

Janson Olstam, J., Lundgren, J., Adlers, M., Matstoms, P., 2008. A framework for simulation of surrounding vehicles in driving simulators. ACM Transactions on Modeling and Computer Simulation 18 (3), 9:1-9:24.

Kesting, A., Treiber, M., Helbing, D., 2007. General lane-changing model MOBIL for car-following models. Transportation Research Record 1999, 86-94.

Leitão, J., Sousa, A., Ferreira, F., 2000. Graphical control of autonomous, virtual vehicles. In: Proceedings of the IEEE Vehicular Technology Conference. Vol. 1. Tokyo, Japan, pp. 507-511.

Olstam, J., Tapani, A., 2010. Enhancements to the intelligent driver model. In: Proceedings of the 89th Annual meeting of the Transportation Research Board. Washington D.C., USA.

Salvucci, D. D., Boer, E. R., Liu, A., 2001. Toward an integrated model of driver behavior in a cognitive architecture. Transportation Research Record 1779, 9-16.

Treiber, M., Hennecke, A., Helbing, D., 2000. Congested traffic states in empirical observations and microscopic simulations. Physical Review E Statistical Physics, Plasmas, Fluids, and Related Interdisciplinary Topics 62 (2), 1805-1824. 
Treiber, M., Kesting, A., Helbing, D., 2006. Delays, inaccuracies and anticipation in microscopic traffic models. Physica A: Statistical Mechanics and its Applications 360, 71-88.

Usoh, M., Catena, E., Arman, S., Slater, M., 2000. Using presence questionnaires in reality. Presence: Teleoperators and Virtual Environments 9 (5), 497-503.

VTI, 2008. Driving simulators at VTI. http://www.vti.se/templates/ Page _-_-_3257 . aspx, accessed October 31, 2008.

Wassink, I., Van Dijk, E., Zwiers, J., Nijholt, A., Kuipers, J., Brugman, A., 2005. Bringing hollywood to the driving school: Dynamic scenario generation in simulations and games. Lecture Notes in Computer Science (including subseries Lecture Notes in Artificial Intelligence and Lecture Notes in Bioinformatics) 3814 LNAI, 288-292.

Wassink, I., Van Dijk, E., Zwiers, J., Nijholt, A., Kuipers, J., Brugman, A., 2006. In the truman show: Generating dynamic scenarios in a driving simulator. IEEE Intelligent Systems 21 (5), 28-32.

Witmer, B. G., Singer, M. J., 1998. Measuring presence in virtual environments: A presence questionnaire. Presence: Teleoperators and Virtual Environments 7 (3), 225-240.

Wright, S., Ward, N. J., Cohn, A. G., 2002. Enhanced presence in driving simulators using autonomous traffic with virtual personalities. Presence: Teleoperators and Virtual Environments 11 (6), 578 - 590. 


\section{List of figure captions}

\section{List of Figures}

1 Illustration of an example combination of the three components in a driving simulator scenario. . . . . . . . . . . . 32

2 Illustration of the problem of transporting an actor from its current speed to a specified relative speed and position with respect to the driving simulator vehicle. . . . . . . . . 33

3 Illustration of how the play preparation problem algorithm (dashed line boxes) is working in each simulation time step. . 34

4 Illustration of the two problem cases of the longitudinal transportation problem for active roles. . . . . . . . . . . 35

5 Illustration of the scenario. . . . . . . . . . . . . . 36

6 Individual speed observations $[\mathrm{km} / \mathrm{h}]$ of all surrounding vehicles within $1 \mathrm{~km}$ ahead or behind subject 1 . The speed profile of subject 1 is shown as a red line. The sample interval is 2 seconds. Note the large variation during the controlled everyday life driving. . . . . . . . . . . . . . . . . . . . . . 37 


\section{List of table captions}

\section{List of Tables}

1 Number of vehicles in the vehicle platoons during the controlled everyday life part. . . . . . . . . . . . . . . . 38

2 Background data about the ten subjects (desired speed in $\mathrm{km} / \mathrm{h}$ ). 39

3 Distance in meters to the driving simulator vehicle for the first no-role actors in play 1 (fog event with $1 \mathrm{~km}$ preparation time and $300 \mathrm{~m}$ minimum distance). . . . . . . . . . . . . . 40

4 Distance in meters to the driving simulator vehicle for the first no-role actors in play 2 (fog event with $2 \mathrm{~km}$ preparation time and $300 \mathrm{~m}$ minimum distance). . . . . . . . . . . . . . 41

5 Distance in meters to the driving simulator vehicle for the first no-role actors in play 3 (braking car event with $2 \mathrm{~km}$ preparation time and 400m minimum distance). . . . . . . . 42

6 Difference between actual and specified distance in meters to the driving simulator vehicle for active roles in play 3 (braking car event with $2 \mathrm{~km}$ preparation time). . . . . . . . . . . 43

7 Difference in percent units between actual and specified speed relative to the driving simulator vehicle for active roles in play 3 (braking car event with $2 \mathrm{~km}$ preparation time). . . . . 44

8 Mean free speed with $95 \%$ - confidence intervals $[\mathrm{m} / \mathrm{s}]$. . . . . 45

9 Difference in mean free speed $[\mathrm{m} / \mathrm{s}]$ between controlled and autonomous everyday life driving or warm-up driving. . . . . . 46

10 T-test statistics for one-sided t-tests regarding higher mean free speed during controlled everyday life traffic than during autonomous everyday life traffic or during warm-up driving. . 47 


\begin{tabular}{c|c|c|c|c|c|c}
\multicolumn{9}{c}{ Curtain up } & $\begin{array}{c}\text { Curtain up } \\
\begin{array}{c}\text { Everyday } \\
\text { life }\end{array}\end{array}$ & $\begin{array}{c}\text { Prepa- } \\
\text { rations }\end{array}$ & Play & $\begin{array}{c}\text { Everyday } \\
\text { life }\end{array}$ & $\begin{array}{c}\text { Prepa- } \\
\text { rations }\end{array}$ & Play & $\begin{array}{c}\text { Everyday } \\
\text { life }\end{array}$ \\
\hline & & manuscript & & Trigger 1 & Trigger 2 & time
\end{tabular}

Figure 1: Illustration of an example combination of the three components in a driving simulator scenario. 


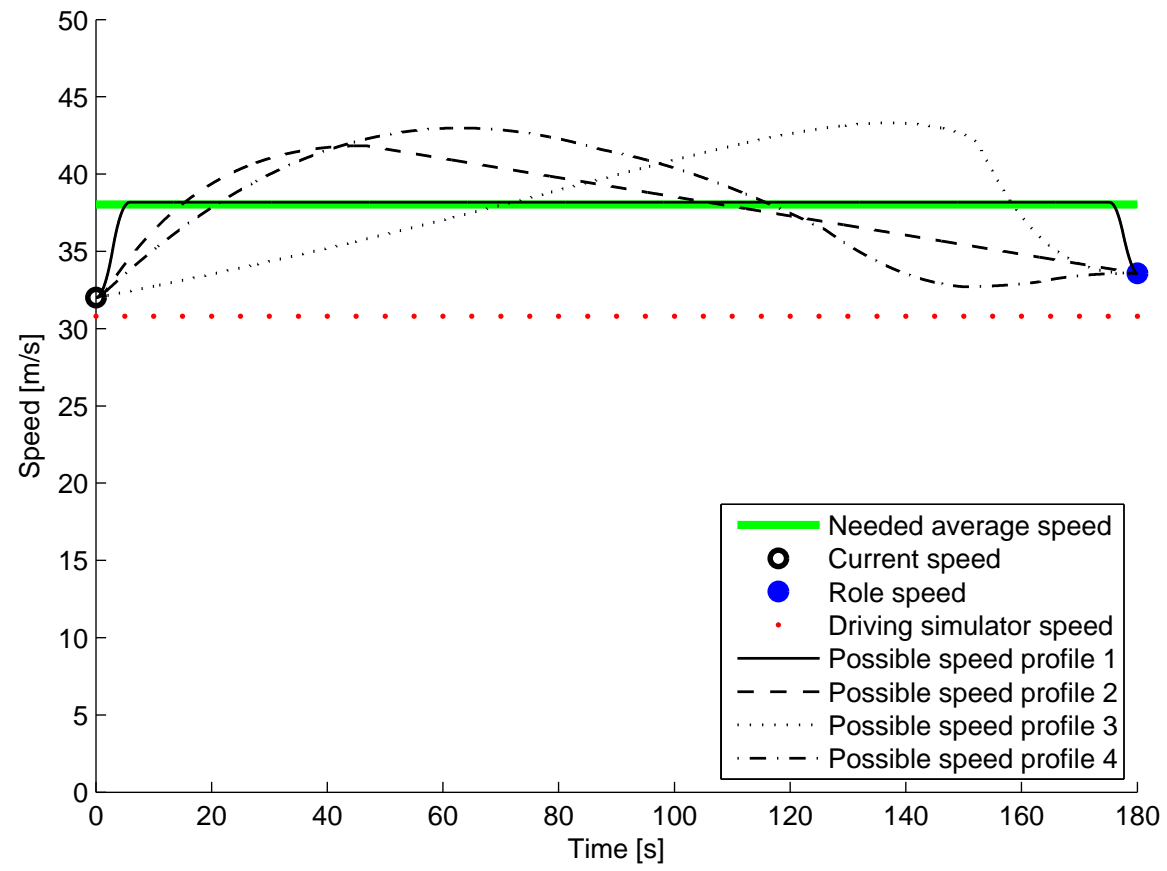

Figure 2: Illustration of the problem of transporting an actor from its current speed to a specified relative speed and position with respect to the driving simulator vehicle. 


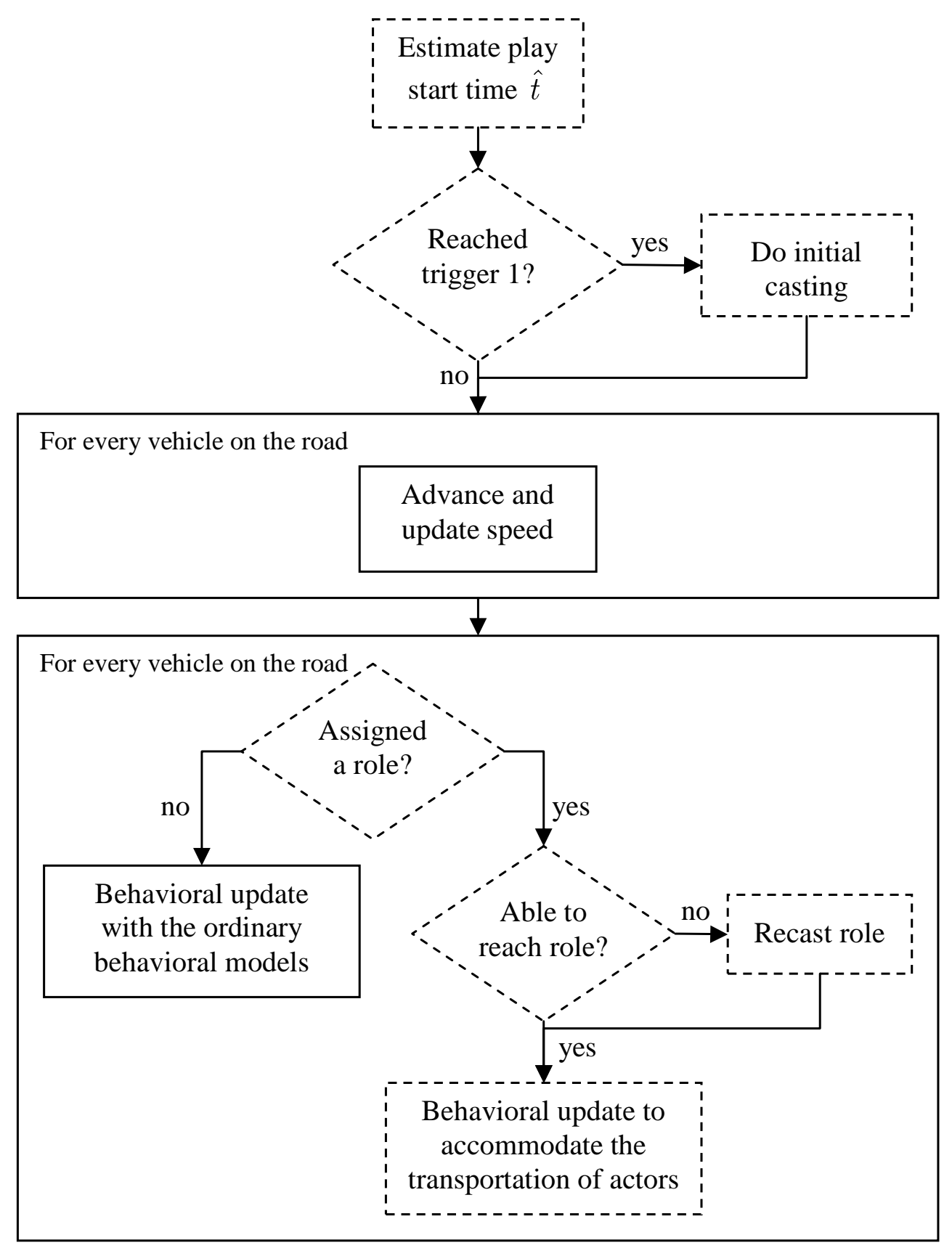

Figure 3: Illustration of how the play preparation problem algorithm (dashed line boxes) is working in each simulation time step. 


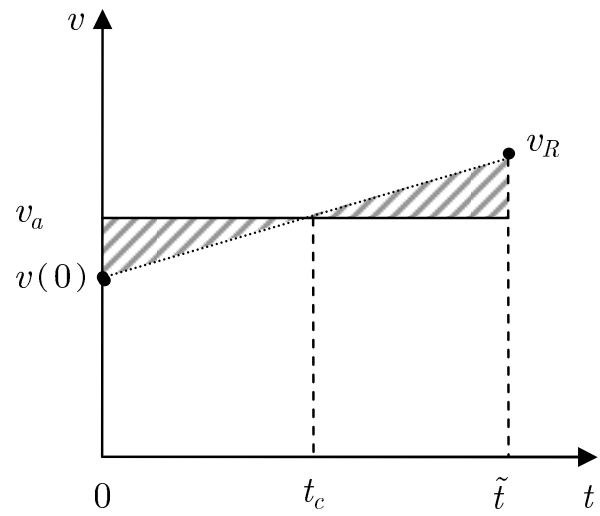

(a)

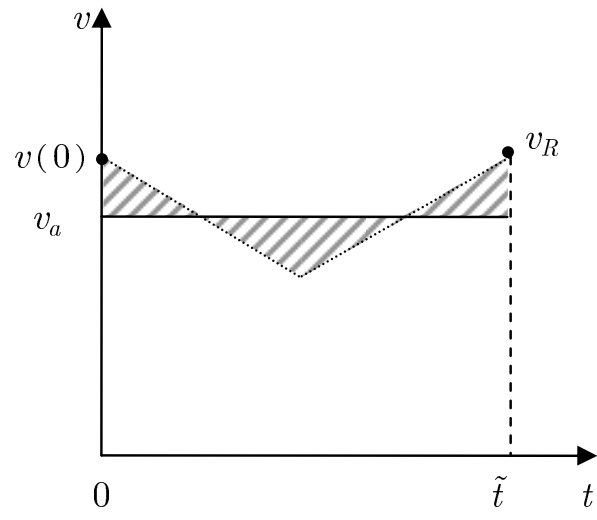

(b)

Figure 4: Illustration of the two problem cases of the longitudinal transportation problem for active roles. 


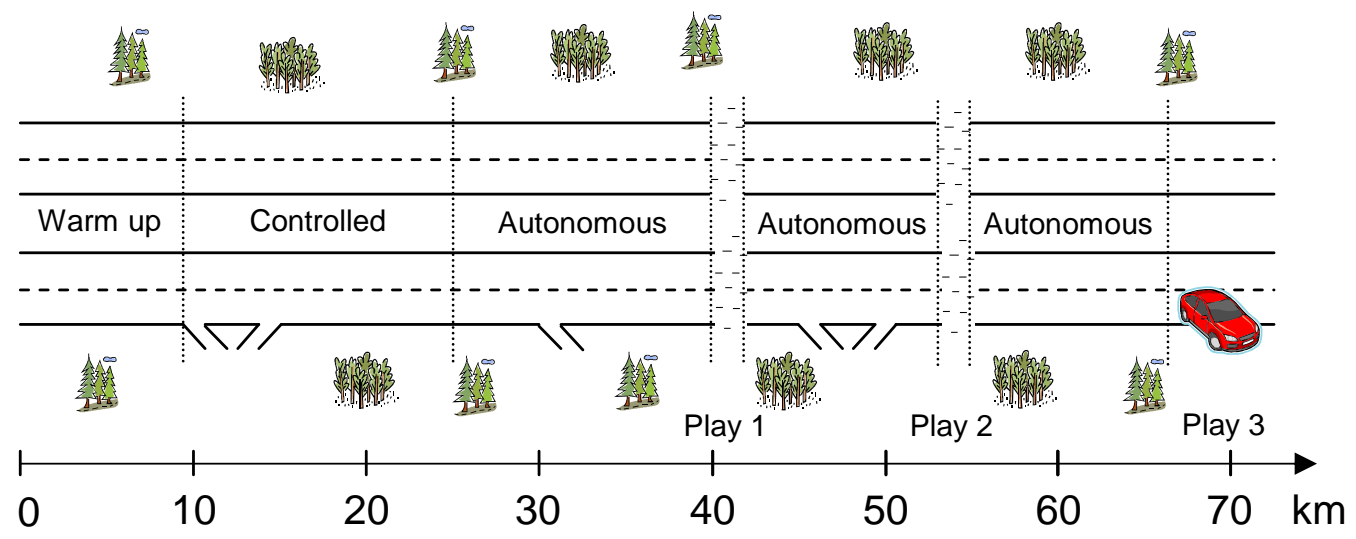

Figure 5: Illustration of the scenario. 


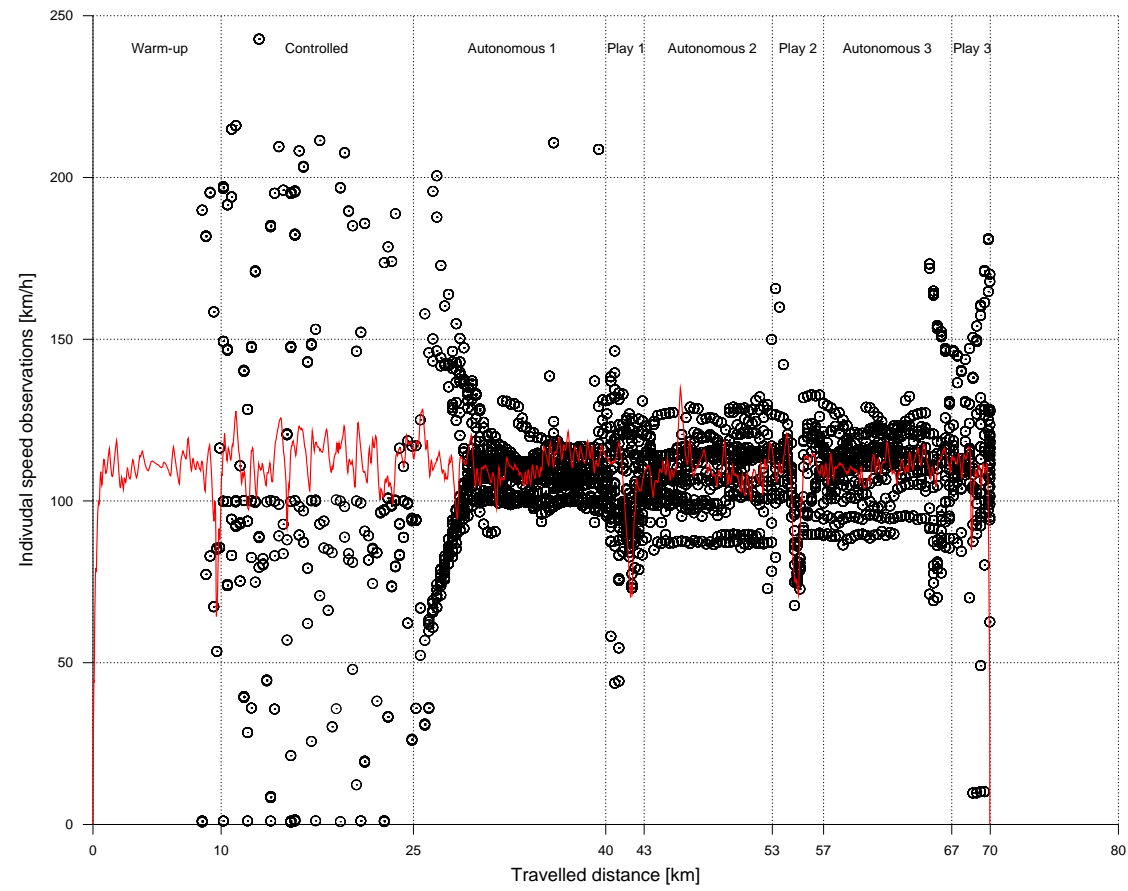

Figure 6: Individual speed observations $[\mathrm{km} / \mathrm{h}]$ of all surrounding vehicles within $1 \mathrm{~km}$ ahead or behind subject 1 . The speed profile of subject 1 is shown as a red line. The sample interval is 2 seconds. Note the large variation during the controlled everyday life driving. 
Table 1: Number of vehicles in the vehicle platoons during the controlled everyday life part.

\begin{tabular}{llllllllll} 
& \multicolumn{10}{c}{ Catch up situation } \\
\hline & 1 & 2 & 3 & 4 & 5 & 6 & 7 & 8 & 9 \\
\hline Fast platoon & 3 & 3 & 0 & 3 & 2 & 0 & 2 & 0 & 1 \\
Slow platoon & 3 & 3 & 1 & 1 & 2 & 1 & 1 & 3 & 3 \\
\hline
\end{tabular}


Table 2: Background data about the ten subjects (desired speed in $\mathrm{km} / \mathrm{h}$ ).

\begin{tabular}{ccccccc}
$\begin{array}{c}\text { Subject } \\
\text { nr }\end{array}$ & Gender & Age & $\begin{array}{c}\text { Years with } \\
\text { license }\end{array}$ & $\begin{array}{c}\text { Mileage } \\
\text { last year }\end{array}$ & $\begin{array}{c}\text { \# of drives } \\
\text { in simulator }\end{array}$ & $\begin{array}{c}\text { Desired } \\
\text { speed }\end{array}$ \\
\hline 1 & F & 36 & 18 & 1000 & 0 & 115 \\
2 & $\mathrm{M}$ & 37 & 20 & 1200 & 15 & 125 \\
3 & $\mathrm{M}$ & 53 & 32 & 1500 & 3 & 120 \\
4 & $\mathrm{~F}$ & 50 & 32 & 500 & 0 & $110-120$ \\
5 & $\mathrm{~F}$ & 60 & 41 & 1000 & 3 & $110-120$ \\
6 & $\mathrm{~F}$ & 29 & 11 & 3000 & 0 & 120 \\
7 & $\mathrm{M}$ & 43 & 23 & 1500 & 0 & 120 \\
8 & $\mathrm{M}$ & 58 & 32 & 1600 & 4 & 110 \\
9 & $\mathrm{M}$ & 25 & 6 & 300 & 1 & 120 \\
10 & $\mathrm{~F}$ & 32 & 13 & 1000 & 0 & 120 \\
\hline
\end{tabular}


Table 3: Distance in meters to the driving simulator vehicle for the first no-role actors in play 1 (fog event with $1 \mathrm{~km}$ preparation time and $300 \mathrm{~m}$ minimum distance).

\begin{tabular}{ccc}
$\begin{array}{c}\text { Subject } \\
\text { number }\end{array}$ & $\begin{array}{c}\text { First no role } \\
\text { behind }\end{array}$ & $\begin{array}{c}\text { first no role } \\
\text { in front }\end{array}$ \\
\hline 1 & -372.2 & 179.1 \\
2 & -480.1 & 142.8 \\
3 & -305.9 & 112.4 \\
4 & -383.3 & 177.2 \\
5 & -350.8 & 339.5 \\
6 & -396.0 & 240.3 \\
7 & -407.7 & 135.9 \\
8 & -377.1 & 29.7 \\
9 & -352.8 & 309.8 \\
10 & -356.6 & 232.1 \\
\hline
\end{tabular}


Table 4: Distance in meters to the driving simulator vehicle for the first no-role actors in play 2 (fog event with $2 \mathrm{~km}$ preparation time and $300 \mathrm{~m}$ minimum distance).

\begin{tabular}{ccc}
$\begin{array}{c}\text { Subject } \\
\text { number }\end{array}$ & $\begin{array}{c}\text { First no role } \\
\text { behind }\end{array}$ & $\begin{array}{c}\text { first no role } \\
\text { in front }\end{array}$ \\
\hline 1 & -268.8 & 340.6 \\
2 & -448.0 & 296.9 \\
3 & -299.5 & 380.7 \\
4 & -449.9 & 344.2 \\
5 & -298.7 & 473.4 \\
6 & -548.0 & 333.8 \\
7 & -286.9 & 318.0 \\
8 & -256.3 & 388.6 \\
9 & -297.1 & 314.8 \\
10 & -351.5 & 243.7 \\
\hline
\end{tabular}


Table 5: Distance in meters to the driving simulator vehicle for the first no-role actors in play 3 (braking car event with $2 \mathrm{~km}$ preparation time and 400m minimum distance).

\begin{tabular}{ccc}
$\begin{array}{c}\text { Subject } \\
\text { number }\end{array}$ & $\begin{array}{c}\text { First no role } \\
\text { behind }\end{array}$ & $\begin{array}{c}\text { first no role } \\
\text { in front }\end{array}$ \\
\hline 1 & -402.0 & 466.9 \\
2 & -500.9 & 341.8 \\
3 & -399.7 & 641.5 \\
4 & -398.8 & 665.8 \\
5 & -979.9 & 577.0 \\
6 & -402.0 & 454.7 \\
7 & -398.4 & 344.4 \\
8 & -400.2 & 419.4 \\
9 & -485.0 & 379.3 \\
10 & -335.0 & 521.2 \\
\hline
\end{tabular}


Table 6: Difference between actual and specified distance in meters to the driving simulator vehicle for active roles in play 3 (braking car event with $2 \mathrm{~km}$ preparation time).

\begin{tabular}{ccccc}
$\begin{array}{c}\text { Subject } \\
\text { number }\end{array}$ & $\begin{array}{c}\text { Behind role } \\
350 \mathrm{~m}\end{array}$ & $\begin{array}{c}\text { Behind role } \\
300 \mathrm{~m}\end{array}$ & $\begin{array}{c}\text { Behind role } \\
250 \mathrm{~m}\end{array}$ & $\begin{array}{c}\text { Front role } \\
400 \mathrm{~m}\end{array}$ \\
\hline 1 & 0.14 & 0.15 & 0.24 & 0.74 \\
2 & -0.21 & -0.29 & -0.14 & 0.18 \\
3 & -0.13 & -0.14 & -0.13 & 0.21 \\
4 & -0.13 & -0.14 & -0.14 & 0.18 \\
5 & -0.13 & -0.15 & -0.11 & 0.24 \\
6 & -0.15 & -0.16 & -0.16 & 0.20 \\
7 & 0.17 & -0.07 & -0.14 & 0.12 \\
8 & -0.14 & -0.15 & -0.14 & 0.22 \\
9 & -0.49 & -0.40 & -0.33 & 0.12 \\
10 & -0.14 & -0.14 & -0.14 & 0.26 \\
\hline
\end{tabular}


Table 7: Difference in percent units between actual and specified speed relative to the driving simulator vehicle for active roles in play 3 (braking car event with $2 \mathrm{~km}$ preparation time).

\begin{tabular}{ccccc}
$\begin{array}{c}\text { Subject } \\
\text { number }\end{array}$ & $\begin{array}{c}\text { Behind role } \\
350 \mathrm{~m}\end{array}$ & $\begin{array}{c}\text { Behind role } \\
300 \mathrm{~m}\end{array}$ & $\begin{array}{c}\text { Behind role } \\
250 \mathrm{~m}\end{array}$ & $\begin{array}{c}\text { Front role } \\
400 \mathrm{~m}\end{array}$ \\
\hline 1 & 2.87 & 2.71 & 3.54 & 2.09 \\
2 & -0.38 & -0.65 & 0.24 & -0.43 \\
3 & 0.49 & 0.21 & 0.69 & -0.27 \\
4 & 0.42 & -0.14 & -0.40 & 0.00 \\
5 & 0.42 & -0.02 & 0.55 & -0.19 \\
6 & -0.15 & 0.01 & -0.71 & 0.33 \\
7 & 3.55 & -1.40 & -1.75 & 0.15 \\
8 & 0.14 & -0.03 & 0.09 & 0.11 \\
9 & -5.01 & -2.81 & -2.08 & -0.30 \\
10 & -0.12 & 0.04 & 0.17 & -0.11 \\
\hline
\end{tabular}


Table 8: Mean free speed with $95 \%$ - confidence intervals $[\mathrm{m} / \mathrm{s}]$.

\begin{tabular}{cccccc} 
Subject & Warm up & Controlled & Autonomous 1 & Autonomous 2 & Autonomous 3 \\
\hline 1 & $30.9 \pm 0.05$ & $32.2 \pm 0.09$ & $31.4 \pm 0.15$ & $30.4 \pm 0.08$ & $30.8 \pm 0.05$ \\
2 & $32.4 \pm 0.08$ & $33.4 \pm 0.08$ & $32.4 \pm 0.08$ & $31.9 \pm 0.14$ & $31.6 \pm 0.10$ \\
3 & $32.8 \pm 0.09$ & $34.9 \pm 0.13$ & $32.2 \pm 0.19$ & $30.6 \pm 0.11$ & $30.2 \pm 0.27$ \\
4 & $30.9 \pm 0.09$ & $32.5 \pm 0.07$ & $30.9 \pm 0.11$ & $30.8 \pm 0.18$ & $30.5 \pm 0.08$ \\
5 & $30.3 \pm 0.03$ & $30.8 \pm 0.07$ & $29.2 \pm 0.09$ & $29.4 \pm 0.07$ & $29.5 \pm 0.08$ \\
6 & $30.3 \pm 0.02$ & $31.1 \pm 0.11$ & $30.0 \pm 0.05$ & $30.1 \pm 0.04$ & $29.9 \pm 0.03$ \\
7 & $34.8 \pm 0.15$ & $34.7 \pm 0.12$ & $33.9 \pm 0.13$ & $31.8 \pm 0.16$ & $34.4 \pm 0.10$ \\
8 & $30.4 \pm 0.03$ & $30.4 \pm 0.04$ & $30.3 \pm 0.03$ & $30.3 \pm 0.05$ & $30.0 \pm 0.04$ \\
9 & $31.6 \pm 0.06$ & $31.7 \pm 0.06$ & $31.6 \pm 0.06$ & $32.0 \pm 0.05$ & $31.9 \pm 0.06$ \\
10 & $32.6 \pm 0.06$ & $32.8 \pm 0.06$ & $32.5 \pm 0.09$ & $32.2 \pm 0.16$ & $30.5 \pm 0.10$ \\
\hline
\end{tabular}


Table 9: Difference in mean free speed $[\mathrm{m} / \mathrm{s}]$ between controlled and autonomous everyday life driving or warm-up driving.

\begin{tabular}{ccccc}
$\begin{array}{c}\text { Subject } \\
\text { nr }\end{array}$ & $\begin{array}{c}\text { Controlled - } \\
\text { Warm up }\end{array}$ & $\begin{array}{c}\text { Controlled - } \\
\text { Autonomous 1 }\end{array}$ & $\begin{array}{c}\text { Controlled - } \\
\text { Autonomous 2 }\end{array}$ & $\begin{array}{c}\text { Controlled - } \\
\text { Autonomous 3 }\end{array}$ \\
\hline 1 & 1.22 & 0.80 & 1.76 & 1.39 \\
2 & 0.91 & 0.99 & 1.48 & 1.72 \\
3 & 2.11 & 2.70 & 4.28 & 4.64 \\
4 & 1.64 & 1.66 & 1.76 & 2.01 \\
5 & 0.44 & 1.52 & 1.36 & 1.24 \\
6 & 0.85 & 1.18 & 1.00 & 1.20 \\
7 & -0.04 & 0.84 & 2.93 & 0.34 \\
8 & 0.04 & 0.06 & 0.05 & 0.40 \\
9 & 0.09 & 0.16 & -0.32 & -0.19 \\
10 & 0.23 & 0.27 & 0.61 & 2.28 \\
\hline
\end{tabular}


Table 10: T-test statistics for one-sided t-tests regarding higher mean free speed during controlled everyday life traffic than during autonomous everyday life traffic or during warm-up driving.

\begin{tabular}{lccc} 
& $\begin{array}{c}\text { Average speed } \\
\text { difference }[\mathrm{m} / \mathrm{s}]\end{array}$ & $\begin{array}{c}95 \% \text { - one sided } \\
\text { confidence interval }\end{array}$ & p-value \\
\hline $\begin{array}{l}\text { Controlled - } \\
\text { Warm up }\end{array}$ & 0.75 & {$[0.32, \infty)$} & 0.0051 \\
\hline $\begin{array}{l}\text { Controlled - } \\
\text { Autonomous 1 }\end{array}$ & 1.02 & {$[0.55, \infty)$} & 0.0015 \\
\hline $\begin{array}{l}\text { Controlled - } \\
\text { Autonomous 2 }\end{array}$ & 1.49 & {$[0.71, \infty)$} & 0.0034 \\
\hline $\begin{array}{l}\text { Controlled - } \\
\text { Autonomous 3 }\end{array}$ & 1.50 & {$[0.73, \infty)$} & 0.0033 \\
\hline
\end{tabular}

